\section{A new ERA?}

\section{A novel component of the European Research Area will require national funders' cooperation.}

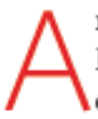

nyone who knows what COST, EURYI, ESF, ELSO, ESOF, EUROHORCS and FENS are probably spends their days deciphering European research policy. These bodies - and there are many more - represent independent Europe-wide initiatives aimed at encouraging scientists and research funding agencies to think European rather than national.

When former European research commissioner Philippe Busquin coined the term European Research Area (ERA) in 2000, he was endorsing such efforts and committing the European Commission to the common aim. But he was also thinking bigger. The vast majority of research money in Europe is in the hands of national funding agencies, which mostly do not allow it to be spent in other countries. In an ideal ERA, national agencies would see the value of sharing much more of their funds in activities for which a larger European scientific community makes sense.

The persistent resistance of many countries in the European Union to this ideal is unsurprising. Nevertheless, the commission has just launched another step towards it: Eurobiofund. This is a new forum that will bring together public and private research funding bodies to listen to pitches from European bioscientists.

The scientists will present hot areas of basic research that they believe need trans-national support if Europe is to remain competitive with the United States and Asia. Funding bodies could sign up to a specific theme, such as lipidomics, and put out a joint call for proposals to be handled by a common evaluation system. They will not necessarily create a shared pot of money, but each could fund their own scientists who win the open competitions. As an incentive for national agencies to flout their own traditions in this way, the commission will top up any joint project with money from its Seventh Framework Programme of Research, which is to be launched at the end of this year.

Funding organizations have signed up to the principle of the Eurobiofund, with the first forum to take place this November in Finland. The commission has given the European Science Foundation (ESF) $€ 1$ million (US\$1.2 million) to set up and run the initiative.

The success of this experiment depends on many factors - in particular, whether its budget is confirmed within the Framework programme, whose "The European Commission will top up any joint project with money from the seventh Framework programme." detailed contents will be defined later this year.

But it also depends on whether agencies are genuinely ready to support joint evaluation procedures. The experience with EURYI the European Young Investigator Awards, which are also administered by the ESF and established by EUROHORCS (the European Heads of Research Councils) - provides grounds for only cautious optimism. Against historical odds, Germany's research council, the DFG, managed to persuade its government to pay into a common financial pot, but then found that other agencies had failed to get similar agreements. As a result, EURYI winners must be funded by their own national agencies. And to make matters worse, British funding agencies have already pulled out of the scheme.

Despite this, Eurobiofund is a positive sign of the commission's willingness to generate ideas for the European Research Area and serve as a catalyst. It may end up being just a small step towards the ideal, but it is the biggest single step that we have seen for some time. European scientists should give it their full support.

\section{Circulation challenge}

\section{The lack of monitoring of ocean currents must be addressed quickly.}

$T$ he idea of a 'mini ice age' triggered by a shutdown of the oceans' thermohaline circulation (THC) has been rich fodder for dramatic scenes from Hollywood to the Pentagon. The currents of the THC take cold surface water from high latitudes southwards at depth, driving low-latitude warm surface waters north. This powerful heat conveyor belt is driven by differences in salt-water density. According to models, if sufficient fresh water is added to the ocean, which could happen as a result of global warming, the THC may cease. Indeed, palaeodimate studies suggest that the THC has shut down a number of times during colder climates in the past 100,000 years.

But most climate researchers have long abandoned the notion of isolated cold regions amidst a globally warming world. It now seems less likely that even a full collapse of the THC - which, although improbable, might still occur towards the end of the century would significantly cool Britain or Scandinavia (see page 256).
The matter is not yet closed, however. A weakening of the THC and recent observations published in Nature have suggested that the currents have begun to change - maylead to perturbations in global climate systems, with unknown side effects. There are many uncertainties, but it is clear that people in Western Europe and eastern North America are less threatened by a consequent rapid climate change (and are more capable of adapting to it) than many people in poorer societies.

More measurements are clearly needed if we are to fill the enormous gaps in our knowledge of ocean behaviour. Autonomous observation tools, such as drifting floats and moored buoys, are now allowing scientists for the first time to monitor the state of the ocean currents almost in real time. This is an
"A weakening of the thermohaline circulation may lead to perturbations in globalclimate systems, with unknown side effects." important advance, but observations must be sustained for much longer periods than foreseen in the six-year RAPID programme (see www.noc.soton.ac.uk/rapid/rapid.php). Furthermore, they should be augmented globally if we are to anticipate possible changes in ocean behaviour with any confidence. 